\title{
Features of optimization of model parameters for solving geotechnical problems
}

\author{
Armen Ter-Martirosyan*, Vitalii Sidorov and Lubov Ermoshina \\ Moscow State University of Civil Engineering, Yaroslavskoe shosse, 26, Moscow, 129337, Russia
}

\begin{abstract}
At present, numerical methods of calculations, which are implemented in a large number of software complexes, are widely used in geotechnical practice and the definition of input parameters of the ground is very important and necessary to reflect the real work of the foundation of geotechnical structures [1-4]. There are often cases when the results obtained during laboratory tests of soils are not accepted by software complexes, errors are given, recommendations are proposed for changing the parameters in the direction of increasing or decreasing. In connection with these problems, the question arose about the need to optimize soil parameters obtained as a result of laboratory tests to compare and correct these parameters, based on the degree of approximation of model tests with laboratory tests [5]. Optimization of soil parameters can be carried out in the subroutine Soil test, incorporated in the PLAXIS geotechnical software [6]. Using the Soil test, the triaxial and compression tests are simulated based on the input parameters of the soil and the initial test data. The purpose of this study was to describe the methodology for optimizing the parameters of the Hardening Soil model and the Soft Soil Creep model using the PLAXIS 3D software geotechnical complex, as well as a comparative analysis of the results of laboratory soil tests with modeling results in software complex.
\end{abstract}

\section{Methods}

In describing the technique for optimizing the parameters of the Hardening Soil model [7-9] and the Soft Soil Creep model [10-13], numerical methods of solution were used. Laboratory studies of soils were carried out on certified equipment in accordance with the current set of rules, and calculation using numerical methods was performed on a certified PLAXIS 3D software package.

In general, the optimization process consists of the sequential execution of the following steps:

1. Processing of protocols of direct laboratory tests, construction of preliminary graphs for estimating the convergence of curves, in order to use only those curves that do not have cardinal differences in behavior in the subsequent calculations, and also bringing information into the form convenient for entering into the subroutine: triaxial tests are

\footnotetext{
* Corresponding author: gic-mgsu@ mail.ru
} 
written in the form two columns, in one of which the deviator voltage $\left(\sigma_{1}-\sigma_{3}\right)$, and in the other - the axial deformation of the sample $\left(\varepsilon_{1}\right)$; Compression tests are written in the form of two columns, in the first of which the vertical stress $\left(\sigma_{y y}\right)$, and in the second - the axial (vertical) deformation - $\left(\varepsilon_{\mathrm{yy}}\right)$.

The data sets for the simulation of triaxial and compression tests should be presented in the format of a text document (.txt).

2. The task in the PLAXIS program in the Materials tab of a set of raw data that was obtained as a result of processing direct laboratory tests of soils.

3. Setting the parameters of the simulation test (triaxial and compression) in the subroutine Soil test.

To simulate a triaxial test, the following parameters are required: Initial cell pressure $\left|\sigma_{\mathrm{xx}}^{\prime}\right|, \mathrm{kN} / \mathrm{m}^{2}$; Maximum strain $\left|\varepsilon_{\mathrm{yy}}\right|, \%$.

To simulate a compression test, the following parameter is required: Stress inc, $\mathrm{kN} / \mathrm{m}^{2}$.

After setting all the necessary parameters, the program builds a series of curves describing the behavior of the ground for given characteristics.

4. Setting the limits of the possible (expected) change of the optimized parameters in the Select parameters tab (all parameters can be optimized or only some of them can be optimized).

5. On the Select curves tab, the prepared text documents with a data set for simulating triaxial and compression tests are downloaded.

6. In the Settings tab, in the Intensity of search line, the degree of accuracy of the calculation is selected.

7. After carrying out all the specified operations, the program selects the correct parameters from the specified range of values.

8. In the Resulting parameters tab, the program shows the values of the optimized parameters and the degree of influence of each optimized parameter on the results.

9. In the Resulting charts tab, you can see the resulting curves - the simulation curve (it is constructed by a subroutine of the given parameters obtained from the simulation results using the subroutine algorithms), the laboratory curve (constructed from real tests of samples in the laboratory) and the optimization curve. The goal of the subroutine is to construct an optimization curve based on the laboratory and simulation curves, which would have a greater degree of convergence with the target (laboratory) curve than with the simulation curve. If the optimization is successful, the program provides an adjusted set of soil parameters

After carrying out the process of optimization of soil parameters, it is necessary to proceed to the modeling of the process of triaxial and compression tests in the PLAXIS 3D software.

\subsection{Modeling of the triaxial test process}

In order to consider the parameters determined as a result of laboratory tests suitable for modeling the behavior of the ground base in software complexes, it will be sufficient to compare the resultant behavior curves of the real ground sample in the instrument and the model sample in the calculation model. To describe the triaxial test, the most indicative curve of the stress deviation $\left(\sigma_{1}-\sigma_{3}\right)$ dependence on vertical deformation $\left(\varepsilon_{1}\right)$ is most often chosen.

The test sample was presented in the model in the form of a cylindrical solid mass (volume) with a diameter of $50 \mathrm{~mm}$ and a height of $100 \mathrm{~mm}$. On the upper face of the cylinder was created a plate element of high rigidity, simulating a hard stamp, through which the vertical load is transferred to the sample. The radial load was set on the side 
surface of the sample with an intensity equal to the reference pressure $p_{\text {ref. }}$. After the model is divided into a finite element grid, a calculation is made that takes into account the following stages:

1) the stage of restoration of the natural stress state (on all surfaces of the sample the same load is applied $\left.\mathrm{p}_{\text {ref }}\right)$;

2) the stage of gradual loading of the sample from the top without changing the lateral pressures (increase of the deviator) to a value $10-15 \%$ lower than $\mathrm{q}_{\mathrm{f}}$ (is analytically);

3 ) unloading stage (gradual reduction of vertical pressure to a value $p_{\text {ref }}$ );

4) the stage of repeated loading and loading to the destruction of the model sample.

Simulation continues until the strength of the specimen is exhausted, which can be determined from the rectilinear portion of the graph, where vertical deformations continue to accumulate at the same (or slightly changing) deviator voltage. Figure 1 shows the stages of modeling the triaxial test process in the PLAXIS 3D software.

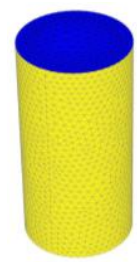

a)

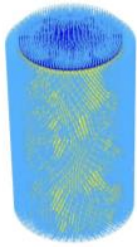

b)

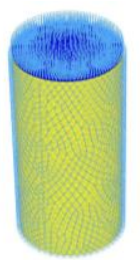

c)

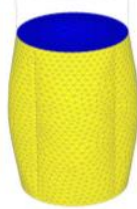

d)

Fig. 1. a - calculated finite element model of the soil sample; $\mathbf{b}$ - calculated finite element model of a sample of soil loaded with a pressure equal to the reference pressure over all surfaces; $\mathbf{c}$ - calculated finite element model of the soil sample at the moment of failure (maximum deviator voltage on the vertical face, deformations not shown); $\mathbf{d}$ - calculated finite element model of the soil sample at the moment of failure (deformed finite element grid).

It should be noted that the shape of the destruction of the sample (Figure 1, d) and the distribution of plastic points (yield surfaces, Fig. 2) corresponds to the forms from real triaxial tests, as well as to classical concepts of fracture processes from soil mechanics.

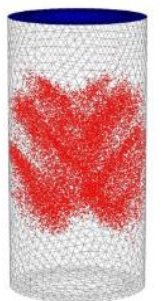

Fig. 2. Distribution of points of plastic deformations in a sample during modeling.

\subsection{Modeling of the compression test process}

To describe the compression test, the curve of the dependence of vertical stresses $\sigma_{\mathrm{yy}}$ on vertical deformation $\varepsilon_{\mathrm{yy}}$ is chosen. The test sample was presented in the model in the form of a cylindrical solid mass (volume) with a diameter of $87 \mathrm{~mm}$ and a height of $25 \mathrm{~mm}$. On the upper side of the cylinder was applied a vertical load on the sample. On the side surfaces, boundary conditions were set whereby lateral expansion of the sample is impossible, but vertical deformations are realized to the full. Figure 3 shows the calculated finite element model of the soil sample under compression conditions, as well as the isopole of vertical displacements in the model soil sample after simulating the compression test. 


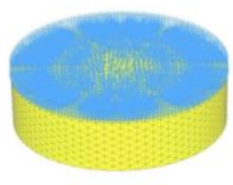

a)

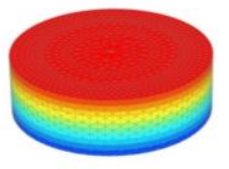

b)

Fig. 3. $\mathbf{a}$ - the calculated finite element model of the soil sample under compression conditions loaded from above; b - isopole of vertical displacements in a model soil sample after simulating a compression test.

\section{Results}

To verify the method for determining the parameters of the Hardening Soil hardening model and the weak soil model, taking into account Soft Soil Creep creep, the test results were selected for two different engineering geological elements (EGE). Their original protocols were processed for a more convenient representation in the form of curves "deviator voltage - vertical deformation" and "vertical stresses - vertical deformation". For each EGE, several triaxial and compression tests have been processed to determine the presence of results strongly knocked out from the general trend values. After that, the results of numerical simulation of triaxial and compression tests were compared with the results of real laboratory tests. The parameters of the Hardening Soil model, obtained from the results of laboratory tests and optimized parameters, are presented in Table 1. The parameters of the Soft Soil Creep model, obtained from direct laboratory tests and optimized soil parameters, are presented in Table 2. In the process of numerical calculations, these data were used, as well as parameters obtained as a result of the optimization carried out using the built-in module PLAXIS Soil test.

Table 1. Summary table of normative values of the parameters of the Hardening Soil model for the considered EGE obtained from the results of direct laboratory tests and optimized parameters of the soil.

\begin{tabular}{|c|c|c|c|c|c|c|c|c|c|c|c|}
\hline & 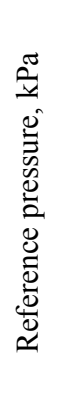 & 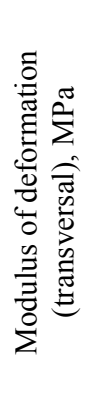 & 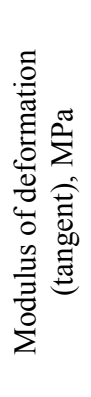 & 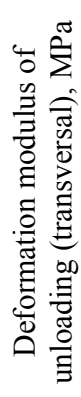 & 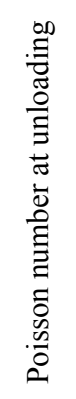 & 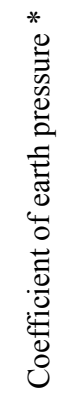 & 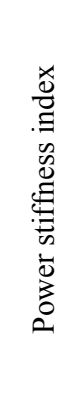 & 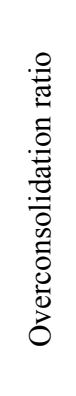 & 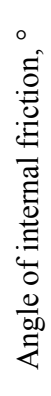 & 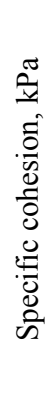 & 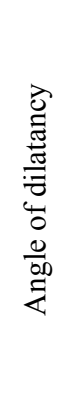 \\
\hline & pref & $\mathrm{E}_{50}{ }^{\mathrm{ref}}$ & Eoed $^{\text {ref }}$ & Eur $^{\text {ref }}$ & Vur & $\mathrm{K}_{0}$ & $\mathrm{~m}$ & $O C R$ & $\varphi$ & $c$ & $\psi,^{\circ}$ \\
\hline \multicolumn{12}{|c|}{ EGE-342 } \\
\hline Lab. & 440 & 33,9 & 54,1 & 158,7 & 0,387 & 0,538 & 0,247 & 1 & 35 & 3 & 1 \\
\hline Opt. & 440 & 24,71 & 47,46 & 158,7 & 0,231 & $\mathbf{0 , 3 9 7}$ & $\mathbf{0 , 8 9 8}$ & 1 & 35 & 3 & 1 \\
\hline \multicolumn{12}{|c|}{ EGE-546 } \\
\hline Lab. & 360 & 44,7 & 21,8 & 110,2 & 0,383 & 0,587 & 0,657 & 1 & 36 & 5 & 0 \\
\hline Opt. & 360 & 33,02 & 19,00 & 110,2 & 0,170 & 0,504 & $\mathbf{0 , 8 1 3}$ & 1 & 36 & 5 & 0 \\
\hline
\end{tabular}




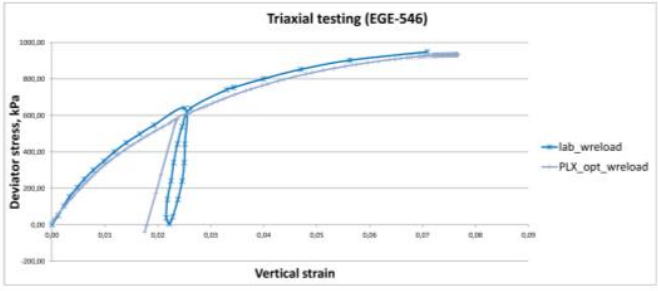

a)

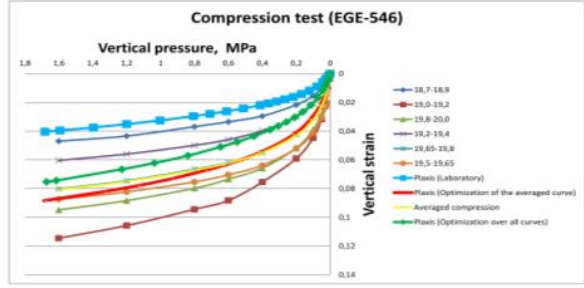

b)

Fig. 4. a - comparison of curves obtained from the results of triaxial tests (lab_wreload) and numerical simulation, taking into account the stages of unloading and re-loading for EGE-546; b comparison of compression curves obtained from the results of laboratory tests (indicated the depth of sampling) and numerical modeling for various parameter processing for EGE-546.

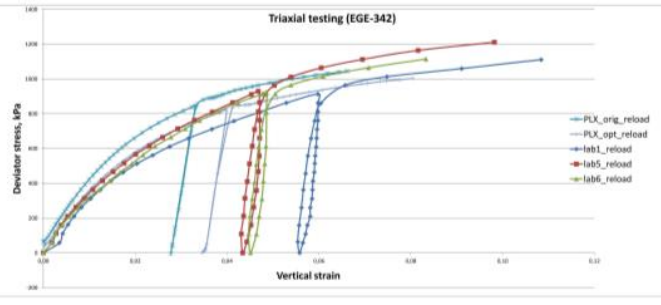

a)

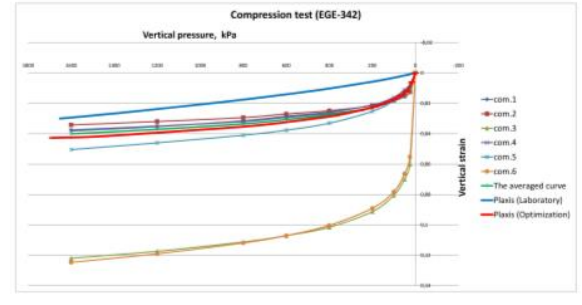

b)

Fig. 5. a - comparison of curves obtained from triaxial tests (lab1_reload, lab5_reload, lab6_reload) and numerical simulation, taking into account the stages of unloading and re-loading using standard laboratory parameters (PLX_orig_reload) and optimized parameters (PLX_opt_reload) for EGE-342; b - comparison of compression curves obtained from the results of laboratory tests (room 1-6) and numerical simulation for various parameter processing for EGE-342.

In Fig. 4a and Fig. 5a presents a comparison of the results of model and direct triaxial tests with an optimized and initial set of parameters. There is a very good convergence both in terms of the magnitude of the deformations obtained (the convergence of the graphs themselves in position - Figure 4a) and in the slopes of all sections of the curves (Figure 4a, Figure 5a), which is the determining factor for the model parameters.

In Fig. $4 b$ and in Fig. 5b shows a comparison of the results of laboratory tests in the compression device and the corresponding model simulations. There is considerable variation in the results of compression tests of different samples of the same EGE selected from comparable depths. In Fig. 5b, the curves of com.6 and com.3 are strongly knocked out from the general "bundle" of tests, which means that these tests must be discarded. Probably, this is due to the natural heterogeneity of the examined soil within one EGE, which is not uncommon. The figures show that the results of the simulation of the compression test using the initial data of the model (Plaxis (laboratory)) showed poor convergence with laboratory curves (Fig. 4b and Fig. 5b). Modeling obtained with optimized parameters of the model made it possible to obtain a curve having good convergence with laboratory curves (Plaxis (optimization of the averaged curve)) - Fig. 4b and (Plaxis (optimization)) - Fig. 5b.

The comparison allows to speak about positive results of verification of the results obtained in the laboratory, obtained in accordance with the methodology for determining the parameters of the Hardening Soil model and their suitability for use in software complexes implementing this model. 
Table 2. Summary table of normative values of the parameters of the Soft Soil Creep model for the considered EGE obtained from the results of direct laboratory tests and optimized parameters of the EGE

\begin{tabular}{|c|c|c|c|c|c|c|c|c|c|c|}
\hline & 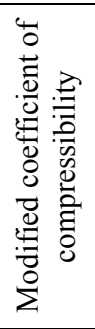 & 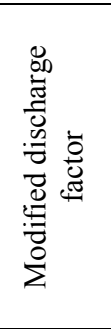 & 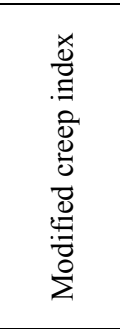 & 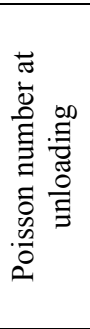 & 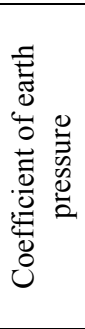 & 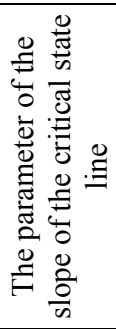 & 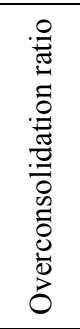 & 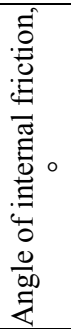 & 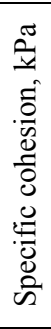 & 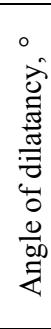 \\
\hline & $\lambda^{*}$ & $\kappa^{*}$ & $\mu^{*}$ & $v_{\mathrm{ur}}$ & $\mathrm{K}_{0}$ & M & $O C R$ & $\varphi$ & $c$ & $\psi^{\circ}$ \\
\hline \multicolumn{11}{|c|}{ EGE-546 } \\
\hline Lab. & 0,0174 & 0,00189 & 0,000687 & 0,383 & 0,587 & 2,04 & 1 & 36 & 5 & 0 \\
\hline Opt. & 0,0150 & 0,00189 & 0,000843 & 0,352 & 0,732 & 1,795 & 1 & 36 & 5 & 0 \\
\hline \multicolumn{11}{|c|}{$\underline{\text { EGE-533 }}$} \\
\hline Lab. & 0,0251 & 0,0016 & 0,00029 & 0,230 & 0,361 & 2,82 & 1 & 23 & 28 & 0 \\
\hline Opt. & 0,0375 & 0,0016 & 0,000082 & 0,409 & 0,969 & 3,83 & 1 & 23 & 28 & 0 \\
\hline
\end{tabular}

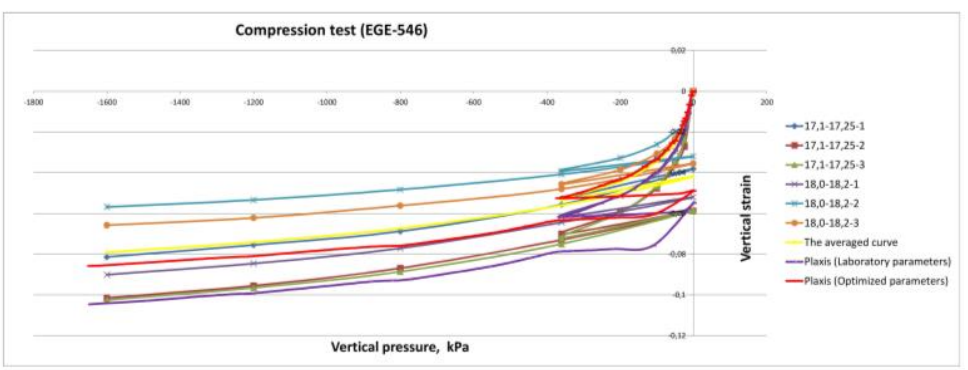

Fig. 6. Comparison of the curves obtained from the results of laboratory tests (indicated the depth of sampling), numerical modeling using the initial soil parameters (Plaxis (Laboratory parameters)) and optimized parameters (Plaxis (Optimized parameters)).

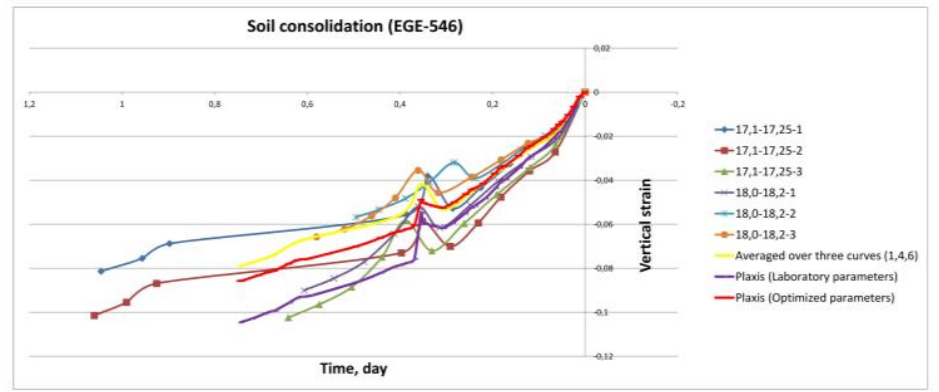

Fig. 7. Comparison of the curves obtained from the results of laboratory tests (indicated the depth of sampling), numerical modeling using the initial soil parameters (Plaxis (Laboratory parameters)) and optimized parameters (Plaxis (Optimized parameters)) in the consolidation regime. 


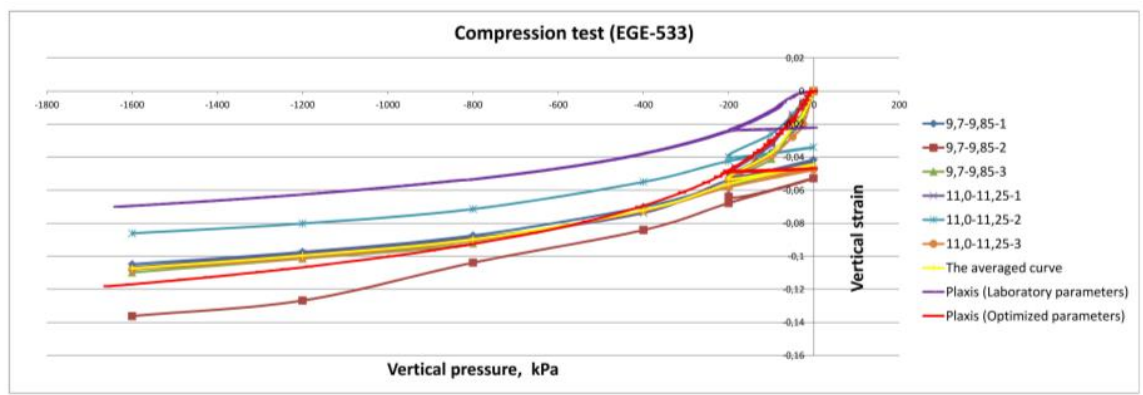

Fig. 8. Comparison of the curves obtained from the results of laboratory tests (indicated the depth of sampling), numerical modeling using the initial soil parameters (Plaxis (Laboratory parameters)) and optimized parameters (Plaxis (Optimized parameters))/

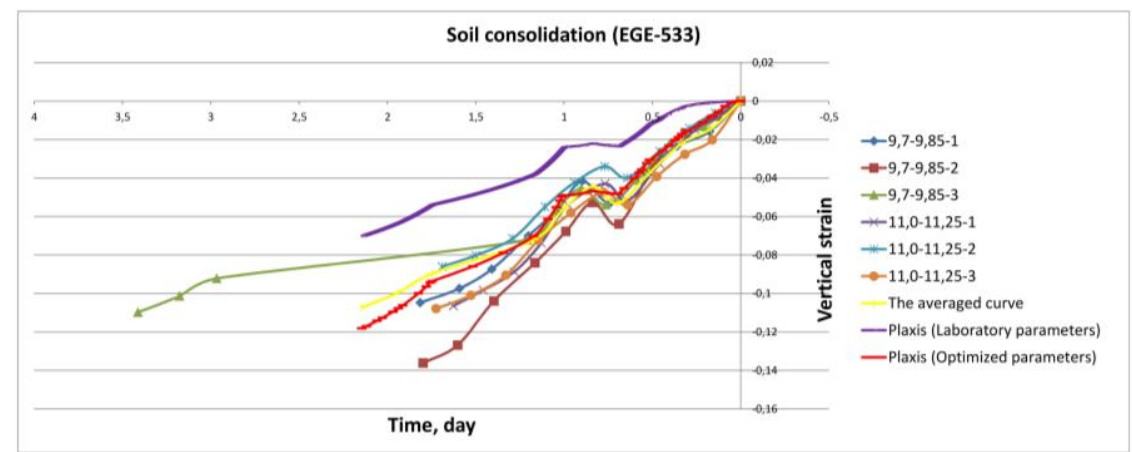

Fig. 9. Comparison of the curves obtained from the results of laboratory tests (indicated the depth of sampling), numerical modeling using the initial soil parameters (Plaxis (Laboratory parameters)) and optimized parameters (Plaxis (Optimized parameters)) in the consolidation regime/

Figures 4-9 show a comparison of the results of simulation tests conducted with the PLAXIS 3D software package with a set of initial and optimized parameters and laboratory test results for several samples for two IGEs selected from near depths. By the position of the graphs, one can note a good convergence of the results. However, one can notice a significant difference in the behavior of the compression curves from samples at close depths.

The model curve (Plaxis (Laboratory parameters)) has a low convergence with the results of direct laboratory tests (compression tests - EGE-546, EGE-533, consolidation tests-EGE-533). Figure 6 shows that the model curve passes below all laboratory curves, and in Figures 8,9 the model curve is located above all laboratory curves. However, the simulation results of consolidation tests for EGE-546 using the initial model data (Plaxis (Laboratory parameters)) showed good convergence with laboratory curves.

The curves obtained from the optimization parameters (Plaxis (Optimized parameters)) obtained from the Soil test subroutine have the best convergence with the entire "bundle" of laboratory curves for all EGE, so we can assume that they describe the average behavior of the material under load.

The comparison allows to speak about the positive results of verification of the results obtained in the laboratory, found in accordance with the methodology for determining the parameters of the SSC model and their suitability for use in software complexes implementing this model. 


\section{Discussion}

An analysis of the scientific literature in this field showed that the optimization of the parameters of the models was described in the work of G.G. Boldyrev, A.Yu. Muizemnek. and D.V. Arefev "Identification of soil model parameters". The authors of the work developed computer models and carried out modeling of soil testing processes in the LSDYNA program, and identification of parameters of the soil model FHWA was performed in the LS-OPT program. The contents of the main stages of identifying the parameters of the sand model are shown in the paper. However, as the authors of the paper write, this technique can be used not only for loose soils, but also for other models of materials, including cohesive and coarse-grained ones. The application of the software of the ASIS measuring and computing complex and the method of identification of soil model parameters considered allows more reliably to assign the parameters used in calculating the stress-strain state of the bases of buildings and structures [14].

R.V. Melnikov was envolved in similar studies with R.Kh. Sagitova. In her work "Calibration of the Hardening Soil model parameters according to the results of laboratory tests in the SoilTest program" the process of step-by-step calibration of parameters of this model in the SoilTest subroutine of the Plaxis program was considered based on the results of laboratory tests. The authors of the work have established that for a reliable description of the actual behavior of the soil, it is necessary to calibrate the parameters of the model, and a sequence of calibrating the model parameters was proposed on the basis of the significance of the parameters in simulating a laboratory test. The study conducted by the authors showed that a reliable determination of parameters depends on the initial stress state. Initially, it is necessary to simulate a triaxial test, and after imitation of compression tests. It was found that the effective dilatancy angle is not significant in simulating neither a triaxial nor a compression test. However, the parameters of the model that have been calibrated allow describing triaxial and compression tests with a high degree of reliability, providing reliability in solving real geotechnical problems [15].

Summarizing the results of this study and analyzing the scientific literature in this area, the following main conclusions can be drawn:

1. The degree of correctness of optimization is determined by the calculator himself, who analyzes the obtained curves, he also makes a decision about whether it is worth using initial parameters or optimized set of them for calculations. This is due to the fact that optimization with the help of the Soil test subprogram is not always able to solve the task as a whole or to solve it correctly. There are cases when a set of input parameters causes errors in the solution and does not lead to results. Or, there are cases when the optimization curve has a worse convergence with the target curve than with the simulation curve, which indicates an unsuccessful course of the subprogram decision.

2. The use of the optimization process also makes it possible to identify and weed out the unsuccessful and out-of-common "bundles" curves that could be obtained erroneously or because of the large heterogeneity of soil properties within one IGE. This is done by loading the entire test suite into the Soil test subroutine. The subroutine will perform the optimization and plot the curves for each laboratory curve. If, for most curves, the optimization curve has reached a high convergence in comparison with the simulation curve, and for one or two tests this has not happened, then it is worthwhile to raise the issue of identifying the reasons for the large differences in the tests and, possibly, the rejection of such results.

3. However, if the rejection of bad results has occurred that have poor convergence in comparison with the simulation curves, then for the remaining curves that have high convergence, it is worthwhile to repeatedly optimize the parameters without taking into account the rejected curves or perform their averaging to one common curve. 
4. When optimizing all curves that have good convergence and when optimizing the averaged curve there can be a small difference in obtaining optimization parameters, otherwise the same result can be obtained if the curves were closely located to each other.

5. To obtain a more correct result, it is worthwhile to average all curves that have a high convergence to one common curve.

6. To improve the degree of convergence of the behavior of model soils in simulations conducted with the help of specialized software complexes, and also to exclude technical errors when accepting input data from the laboratory by calculation programs, it is recommended to apply the optimization technique described in the work or proceed to direct verification tests with the use of soil parameters for the design and calculation of the foundations of buildings and structures of increased responsibility and unique.

7. The technique obtained is relevant for use in the processing of test results to determine the parameters of the model of hardening soil.

The technique presented in the article on optimization of the parameters of the hardening soil model allows to estimate the degree of correctness of the simulation of the soil massif behavior in the software complex with respect to the behavior of the ground sample in laboratory instruments. This is necessary for designers and accountants, since it is important to know the degree of approximation of modeling in the software complex to the behavior of the ground in the process of real testing.

This work was financially supported by the Ministry of Education and Science (state task \# 7.3225.2017/4.6). All tests were carried out using research equipment of The Head Regional Shared Research Facilities of the Moscow State University of Civil Engineering.

\section{References}

1. Chislennye metody raschetov $v$ prakticheskoj geotekhnike (Numerical methods of calculations in practical geotechnics) (SPbGASU, S. Pet., 2012)

2. A.Z. Ter-Martirosyan, A.Yu. Mirnyi, V.V. Sidorov, Laboratornye ispytaniya v MGSU (Laboratory tests in NRU MGSU), Eng. research, 8, 60-65 (2013)

3. G.G. Boldyrev, Metody opredeleniya mekhanicheskikh svojstv gruntov (Methods for determining the mechanical properties of soils) (PGUAS, Penza, 2008)

4. L.A. Strokova, Opredelenie parametrov dlya chislennogo modelirovaniya povedeniya gruntov (Determination of parameters for numerical simulation of soil behavior), Bulletin of TPU, 313, No.1, 69-74 (2008)

5. L.A. Strokova, 2009. Korrektirovka parametrov uprugosti uprugoplasticheskoj modeli putem modelirovaniya laboratornykh ispytanij (Correction of the elasticity parameters of the elastoplastic model by modeling laboratory tests), Bulletin of TPU, 315, No.1, 87-92 (2009)

6. R.B.J. Brinkgreve, E. Engin, W.M. Swolfs PLAXIS 2D 2010 user manual (Plaxis bv., Deft, 2010)

7. A.Z. Ter-Martirosyan, A.Yu. Mirnyi, Analiz statisticheskoj izmenchivosti parametrov modeli Hardening Soil (Analysis of statistical variability of Hardeding soil model parameters), Engineering-geological problems of the present and methods for their solution, 192-197 (2017)

8. K.V. Slivets, Opredelenie vnutrennikh parametrov modeli Hardening Soil (Determining the internal parameters of the Hardening Soil model), Geot., 6, 55-59 (2010)

9. A.Yu. Mirnyi, Trekhosnye ispytaniya gruntov: teoriya i praktika (Three-axis tests of soils: theory and practice) (Geomarketing, Moscow, 2015) 
10. A.A. Korshunov, Opredelenie parametrov modeli Soft Soil Creep v PLAXIS po rezul'tatam issledovaniya peschano-glinistykh otkhodov obogashheniya kimberlitovykh rud mestorozhdeniya almazov (Determination of the Soft Soil Creep model parameters in PLAXIS based on the results of a study of sand and clay wastes of kimberlite ore enrichment in diamond fields), Bulletin PNRPU. Builning and architecture, 1, 136-143 (2013)

11. V.G. Ofrikhter, Ya.V. Ofrikhter, Prognoz napryazhenno-deformirovannogo sostoyaniya tverdykh bytovykh otkhodov s ispol'zovaniem modeli slabogo grunta (Forecast of the stress-strain state of solid household waste using the model of weak ground), Bulletin MGSU, 9, 82-92, (2014)

12. P.A. Konovalov, S.G. Bezvolev, Analysis of results of consolidation tests of saturated clayey soils, Soil Mech. and Found. Eng., 42 No.3, 81-85 (2005)

13. H. Sekiguchi, Rheological characteristics of clays, $9^{\text {th }}$ ICSMFE, Tokyo, 1, 289-292 (1977)

14. A.Yu. Muizemnek, G.G. Boldyrev, D.V. Arefev, Identifikatsiya parametrov modelej gruntov (Identification of soil model parameters), Eng. Geol., 3, 38-43 (2010)

15. R.V. Melnikov, R.Kh. Sagitova, Kalibrovka parametrov modeli Hardening Soil po rezul'tatam laboratornykh ispytanij v programme (Calibration of the Hardening Soil model parameters according to the results of laboratory tests in the SoilTest program) Akadem. Vestnik UralNIIproekt RAASN, 3, 79-83 (2016) 